\title{
Author Correction: Integration of human adipocyte chromosomal interactions with adipose gene expression prioritizes obesity-related genes from GWAS
}

\author{
David Z. Pan ${ }^{1}{ }^{2}$, Kristina M. Garske ${ }^{1}$, Marcus Alvarez ${ }^{1}$, Yash V. Bhagat ${ }^{1}$, James Boocock ${ }^{1}$, Elina Nikkola ${ }^{1}$, \\ Zong Miao ${ }^{1,2}$, Chelsea K. Raulerson ${ }^{3}$, Rita M. Cantor ${ }^{1}$, Mete Civelek (1D ${ }^{4}$, Craig A. Glastonbury ${ }^{5}$, \\ Kerrin S. Small (10 ${ }^{6}$, Michael Boehnke ${ }^{7}$, Aldons J. Lusis ${ }^{1}$, Janet S. Sinsheimer ${ }^{1,8}$, Karen L. Mohlke ${ }^{3}$, \\ Markku Laakso9 ${ }^{9}$ Päivi Pajukanta ${ }^{1,2,10}$ \& Arthur Ko (i) 1,10
}

Correction to: Nature Communications https://doi.org/10.1038/s41467-018-03554-9, published online 17 April 2018

In the original version of this Article, Supplementary Table 10 contained incorrect primer sequences for the mobility shift assay for SNP rs4776984. These errors have now been fixed and the corrected version of the Supplementary Information PDF is available to download from the HTML version of the Article.

Published online: 22 August 2018

\begin{abstract}
(c) (i)
Open Access This article is licensed under a Creative Commons Attribution 4.0 International License, which permits use, sharing, adaptation, distribution and reproduction in any medium or format, as long as you give appropriate credit to the original author(s) and the source, provide a link to the Creative Commons license, and indicate if changes were made. The images or other third party material in this article are included in the article's Creative Commons license, unless indicated otherwise in a credit line to the material. If material is not included in the article's Creative Commons license and your intended use is not permitted by statutory regulation or exceeds the permitted use, you will need to obtain permission directly from the copyright holder. To view a copy of this license, visit http://creativecommons.org/licenses/by/4.0/.
\end{abstract}

(C) The Author(s) 2018

\footnotetext{
${ }^{1}$ Department of Human Genetics, David Geffen School of Medicine at UCLA, Los Angeles, CA 90095, USA. ${ }^{2}$ Bioinformatics Interdepartmental Program, UCLA, Los Angeles, CA 90095, USA. ${ }^{3}$ Department of Genetics, University of North Carolina, Chapel Hill, NC 27599, USA. ${ }^{4}$ Department of Biomedical Engineering, University of Virginia, Charlottesville, VA 22904, USA. ${ }^{5}$ Big Data Institute, University of Oxford, Oxford OX3 7LF, UK. ${ }^{6}$ Department of Twin Research and Genetic Epidemiology, King's College, London, UK. ${ }^{7}$ Department of Biostatistics, University of Michigan, Ann Arbor, MI 48109, USA. ${ }^{8}$ Department of Biomathematics, David Geffen School of Medicine at UCLA, Los Angeles, CA 90095, USA. ${ }^{9}$ Institute of Clinical Medicine, Internal Medicine, University of Eastern Finland and Kuopio University Hospital, Kuopio FI-70210, Finland. ${ }^{10}$ Molecular Biology Institute at UCLA, Los Angeles, CA 90095, USA. These authors contributed equally: David Z. Pan, Kristina M. Garske. Correspondence and requests for materials should be addressed to A.K. (email: a5ko@ucla.edu)
} 